\title{
Role of Muramyl Dipeptide in Lipopolysaccharide-Mediated Biological Activity and Osteoclast Activity
}

\author{
Hideki Kitaura (D, Masahiko Ishida, Keisuke Kimura, Haruki Sugisawa, Akiko Kishikawa, \\ Kazuhiro Shima, Saika Ogawa, Jiawei Qi, and Wei-Ren Shen \\ Division of Orthodontics and Dentofacial Orthopedics, Department of Translational Medicine, Tohoku University Graduate School of \\ Dentistry, 4-1 Seiryo-machi, Aoba-ku, Sendai 980-8575, Japan \\ Correspondence should be addressed to Hideki Kitaura; hkitaura@m.tohoku.ac.jp
}

Received 28 September 2017; Accepted 10 January 2018; Published 14 February 2018

Academic Editor: Jonathan S. Reichner

Copyright (C) 2018 Hideki Kitaura et al. This is an open access article distributed under the Creative Commons Attribution License, which permits unrestricted use, distribution, and reproduction in any medium, provided the original work is properly cited.

\begin{abstract}
Lipopolysaccharide (LPS) is an endotoxin and bacterial cell wall component that is capable of inducing inflammation and immunological activity. Muramyl dipeptide (MDP), the minimal essential structural unit responsible for the immunological activity of peptidoglycans, is another inflammation-inducing molecule that is ubiquitously expressed by bacteria. Several studies have shown that inflammation-related biological activities were synergistically induced by interactions between LPS and MDP. MDP synergistically enhances production of proinflammatory cytokines that are induced by LPS exposure. Injection of MDP induces lethal shock in mice challenged with LPS. LPS also induces osteoclast formation and pathological bone resorption; MDP enhances LPS induction of both processes. Furthermore, MDP enhances the LPS-induced receptor activator of NF- $\kappa \mathrm{B}$ ligand (RANKL) expression and toll-like receptor 4 (TLR4) expression both in vivo and in vitro. Additionally, MDP enhances LPSinduced mitogen-activated protein kinase (MAPK) signaling in stromal cells. Taken together, these findings suggest that MDP plays an important role in LPS-induced biological activities. This review discusses the role of MDP in LPS-mediated biological activities, primarily in relation to osteoclastogenesis.
\end{abstract}

\section{Introduction}

Lipopolysaccharide (LPS) is a major component of the cell wall of Gram-negative bacteria and is an inflammationinducing endotoxin [1-6]. Exposure to LPS can induce proinflammatory cytokines, such as tumor necrosis factor(TNF-) $\alpha$ and interleukin- (IL-) 1, from macrophages or other cells in the affected area $[7,8]$. Peptidoglycan (PGN) is a major component of the cell membranes of both Gramnegative and Gram-positive bacteria. Muramyl dipeptide (MDP) is the minimal essential structural unit of PGN responsible for its immunological activity. Coinjection of MDP and LPS into mice enhances production of proinflammatory cytokines, compared with monoinjection of LPS [9]. Further, it has been reported that injection of MDP induces lethal shock in mice challenged with LPS [10]. Furthermore, LPS and MDP synergistically induce proinflammatory cytokine expression in monocyte cell culture [11].
Osteoclast formation is dependent upon stimulation by receptor activator of NF- $\kappa$ B ligand (RANKL) and macrophage colony-stimulating factor (M-CSF) [12]. Additionally, it has been reported that TNF- $\alpha$ induces osteoclast formation $[13-16]$ and induces in vivo $[17,18]$. These cytokines also contribute to LPS-induced osteoclast formation and bone destruction [1, 2, 19-23]; MDP has also been shown to enhance LPS-induced osteoclast formation [24]. These findings suggest that MDP might play an important role in LPSinduced biological activities. Therefore, LPS and MDP are targets of therapies against bacterially induced inflammation.

This review discusses the role of MDP in LPS-mediated biological activities, primarily in relation to osteoclastogenesis.

\section{Biological Effect of LPS and MDP}

LPS localizes within the outer layer of the membrane and is present on the cell surface of Gram-negative bacteria. LPS 


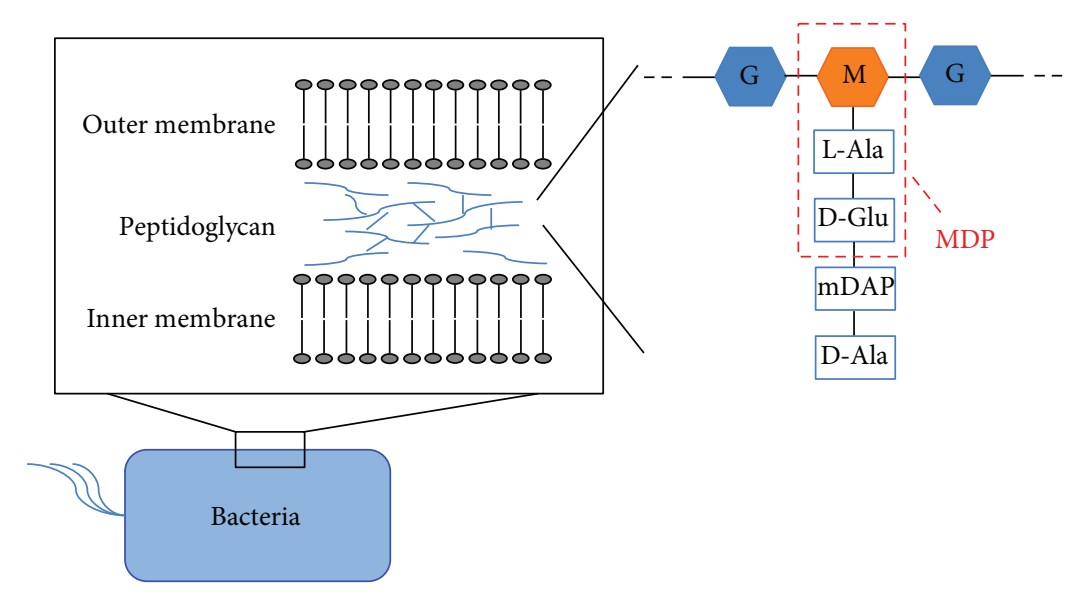

FIGURE 1: Schematic structure of peptidoglycan and MDP. PGN, a major component of the bacterial cell membrane, is a crystal lattice structure formed by the combination of linear chains of two alternating amino sugars, GlcNAc and MurNAc. MDP consists of MurNAc and two amino acids, L-Ala and D-Glu. M: MurNAc; G: GluNAc.

molecules are made up of three structural components: lipid A, a hydrophobic lipid section, which is responsible for the toxicity of the molecule; a hydrophilic polysaccharide chain that serves as the core of the molecule; and a repeating hydrophilic O-antigenic oligosaccharide side chain that is specific to each bacterial species $[25,26]$.

LPS induces its action through interactions with toll-like receptor 4 (TLR4) on the cell membrane of a target host cell. First, LPS binds to the serum protein LPS-binding protein (LBP) $[27,28]$; then, LPS is transferred to CD14 by the catalytic activity of LBP $[29,30]$. Although this LPS-CD14 complex binds to TLR4, the MD-2 molecule is essential for the recognition of LPS by TLR4 [31]. Thus, LPS ultimately binds a CD14/TLR4/MD-2 receptor complex; this is present in many cell types, including monocytes, dendritic cells, macrophages, and B cells. When stimulated by LPS, these cells produce inflammatory cytokines, nitric oxide, and prostaglandin (PGE) [32-36]. Through this mechanism, LPS induces production of many local factors, including TNF- $\alpha$ and IL-1, from macrophages and other cells involved in mediating the inflammatory response within tissues $[37,38]$.

PGN, another major component of the bacterial cell membrane, is a crystal lattice structure formed by the combination of linear chains of two alternating amino sugars, Nacetylglucosamine (GlcNAc) and $\mathrm{N}$-acetylmuramic acid (MurNAc) [39, 40]. MDP is the minimal essential structural unit responsible for the immunological activity of a wide variety of PGNs (Figure 1). Nucleotide-binding oligomerization domain (NOD) 1 and NOD2 are involved in the recognition of PGN in the cytosol of the cells. MDP is recognized via NOD2 [41, 42]. MDP is also the most basic structure required to maintain the efficacy of Freund's complete adjuvant (FCA). FCA induces both humoral and cellular immune responses. However, the toxicity of FCA is very strong, which makes it difficult to use for clinical applications. Therefore, investigators determined that the smallest biologically active component in FCA was tripeptide-monosaccharide MDP [43] and that this compound maintains adjuvant activity. Thus, MDP replaced FCA in protocols requiring the induction of both humoral and cellular activities. However, MDP cannot induce immunoglobulin production when it is the sole adjuvant [43-45].

When MDP is used as the sole adjuvant, it enhances the expression of cell adhesion molecules and antigen presentation. Therefore, phagocytic activity, antimicrobial activity, and antibody-mediated cytotoxicity are enhanced [46-51]. Additionally, MDP induces immune responses through increased cytokine production, enhancing the differentiation and proliferation of $\mathrm{T}$ lymphocytes and subsequent protection against foreign intruders [52-55]. Therefore, MDP serves as an effective adjuvant and may be used to boost the potency of drugs and vaccines.

It has been reported that preexposure to MDP increases immune responses to later challenges. Notably, MDP induced expression of TNF- $\alpha$ when injected into mice [9]; in subsequent studies, MDP-induced production of TNF- $\alpha$ resulted in lethal shock in mice that were challenged with LPS [10]. In addition, MDP has been shown to synergistically enhance production of proinflammatory cytokines elicited by LPS stimulation of human monocyte cells [11]. Several studies have reported this synergistic effect when MDP is combined with LPS; it was observed in studies of primary cells, such as peripheral blood mononuclear cells (PBMCs), purified monocytes, and various cell lines in vitro [11, 56-61].

In other investigations, MDP was reported to enhance the protective response of interferon- (IFN-) $\alpha$ and IFN- $\beta$ against encephalomyocarditis virus infection [62]. MDP conjugated to PolyG (a 10-mer polyguanylic acid) enhanced the secretion of IL- 6 , IL- 1 , TNF- $\alpha$, and nitric oxide; this resulted in the activation of macrophages with tumoricidal activity $[63,64]$. Further, exposure to paclitaxel-conjugated MDP increased antitumor activity [65] and enhanced the expression of TNF- $\alpha$ and IL-12 by mouse peritoneal macrophages [66].

MDP and its derivatives, such as murabutide (MB), have potential for a variety of clinical applications. MB enhances resistance against bacterial and viral infections, such as infection by human immunodeficiency virus (HIV) [67-72]. MB stimulation inhibited HIV replication in macrophages via NOD2 signaling [73]. Human PBMCs that were stimulated 
in vitro with IL-2 and murabutide showed synergistic induction of IFN- $\gamma$ expression [74]. Combined administration of $\mathrm{MB}$ and IL-2 into Meth-A sarcoma-bearing mice resulted in significant tumor inhibition and complete tumor regression in $70 \%$ of treated mice [74].

\section{The Role of MDP and LPS in Osteoclast Formation and Bone Remodeling}

Osteoclasts develop from myeloid lineage cells; they function to resorb bone and control bone remodeling [12]. In osteolytic diseases, both the formation and activity of osteoclasts are exceptionally stimulated [75]. The osteoclast is considered central to diseases involving bone erosion, such as rheumatoid arthritis [75], periprosthetic bone loss [76], postmenopausal osteoporosis [77, 78], and periodontal disease [1, 79].

LPS induces production of proinflammatory cytokines, such as TNF- $\alpha$ and IL-1, from macrophages and other cells in affected tissues [7]. The production of TNF- $\alpha$ and IL-1 is associated with LPS-induced osteoclast formation and bone destruction in vivo and in vitro [1, 2, 19-22]. Further, LPS stimulates osteoblasts to produce RANKL [80].

In contrast, a variety of cytokines, including IL-4, IL-10, IL-12, IL-13, IL-18, and IFN- $\gamma$, are able to inhibit osteoclast formation [81]. Furthermore, some cytokines, such as IL-4, have direct inhibitory effects on osteoclast formation by modifying the effects of RANKL and TNF- $\alpha$ on osteoclast precursor cells [82-85].

Several papers have reported that LPS-induced osteoclast formation in vivo is inhibited by exposure to a variety of cytokines, such as IL-4, IFN- $\gamma$, IL-12, and IL-37. IL-4 and IFN- $\gamma$ were found to directly inhibit LPS-induced differentiation of osteoclast precursors into osteoclasts [86]. In vivo IL-12 stimulation inhibits LPS-induced osteoclastogenesis. mRNA levels of both Fas and FasL increased in mice that were coadministered LPS and IL-12; this might lead to apoptotic changes in osteoclastogenesis-related cells through Fas/ FasL interactions [87]. In vivo IL-37 stimulation inhibited LPS-induced osteoclast formation and bone resorption via inhibition of LPS-induced osteoclast-related cytokines. However, IL-37 might act indirectly to inhibit osteoclast formation by osteoclast precursor cells and RANKL expression by stromal cells [88].

MDP stimulation can enhance osteoclast formation that is initially induced by LPS, IL- $1 \alpha$, or TNF- $\alpha$, but not by $1 \alpha, 25$-dihydroxy-vitamin-D3 $(1 \alpha, 25(\mathrm{OH}) 2 \mathrm{D} 3)$ or PGE2. Furthermore, MDP upregulated RANKL expression in osteoblasts treated with LPS or TNF- $\alpha$, but not with $1 \alpha, 25(\mathrm{OH}) 2 \mathrm{D} 3$ [89]. However, MDP alone cannot induce osteoclast formation in cocultures of primary murine osteoblasts and hematopoietic cells.

The in vitro effects of PGN on LPS-induced osteoclast formation and bone resorption have been investigated. Furthermore, during a set of in vivo studies, PGN significantly induced osteoclast formation and bone resorption in mice coinjected with LPS [90]. Since MDP is the minimal essential structural unit responsible for the immunological activity of PGN, we suspect that MDP plays an important role in the ability of PGN to enhance LPS-induced osteoclast formation and bone resorption.

Recently, the effect of MDP in LPS-induced osteoclast formation and bone resorption has been reported. In that study, LPS was administered as a monoinjection, or as a coinjection with MDP, into the supracalvariae of mice. Compared with mice that received a monoinjection of LPS, mice that received a coinjection of LPS and MDP exhibited an increase in the following parameters: number of osteoclasts, levels of cathepsin K mRNA and tartrate-resistant acid phosphatase (TRAP) mRNA, ratio of bone destruction area and levels of TRAP 5b (TRACP5b), and C-terminal telopeptide fragments of type I collagen (a marker of bone resorption). In contrast, exposure to MDP alone had no effect on osteoclastogenesis in PTH-stimulated mice. These results suggest that MDP enhances LPS-induced osteoclast formation and bone resorption [24].

LPS has been shown to enhance the production and secretion of RANKL by osteoblasts [80]. A later in vitro study of osteoblasts that were cultured with LPS alone, or with a combination of LPS and MDP, indicated that MDP stimulation enhances LPS-induced expression of RANKL mRNA in osteoblasts [89]. Another study showed that MDP enhances LPS-induced expression of RANKL mRNA in stromal cells [24], which supported previous findings. However, these results indicate that MDP alone cannot induce RANKL expression, either in vitro or in vivo, and that MDP is only able to enhance the effects of LPS exposure (e.g., RANKL expression). In contrast, MDP cannot enhance PTH-induced osteoclast formation and bone resorption, suggesting that MDP affects LPS signaling but not PTH-induced signaling [24].

LPS is recognized by TLR4 on the host cell surface [91-93]. TLR4 signaling generates proinflammatory host defense processes [94-97]. During osteoclast formation, stromal cells, such as osteoblasts, express RANKL. It has been reported that LPS induces an increase in TLR4 expression in stromal cells. Furthermore, MDP has been shown to enhance LPS-induced upregulation of TLR4 expression in stromal cells. However, PTH stimulation does not enhance TLR4 expression, suggesting that MDP enhances LPS signaling by increasing TLR4 expression [24]. Taken together, these results indicate that MDP enhances LPS-induced RANKL expression and TLR4 expression in stromal cells.

Costimulation of osteoblasts, using a combination of NOD1 or NOD2 ligands and TLR2 or TLR4 ligands, has been reported to enhance the expression of cyclooxygenase(COX-) 2, PGE2, IL-1 $\beta$, IL-6, and IL-8 through an increase in TRAF6 expression [98]. MDP stimulation synergistically increased RANKL expression in osteoblasts that were costimulated with LPS, IL- $1 \alpha$, and TNF- $\alpha$; this costimulation enhances osteoclast formation [89]. LPS has been reported to induce the phosphorylation of MAPKs (ERK, P38, and JNK) in osteoblasts $[99,100]$. MDP has also been reported to enhance LPS-stimulated ERK1/2 phosphorylation in osteoblasts [89]. Furthermore, although MDP alone cannot activate MAPKs, MDP enhances LPS-induced MAPK phosphorylation in stromal cells. Thus, MDP appears to enhance LPS-related signal transduction. 


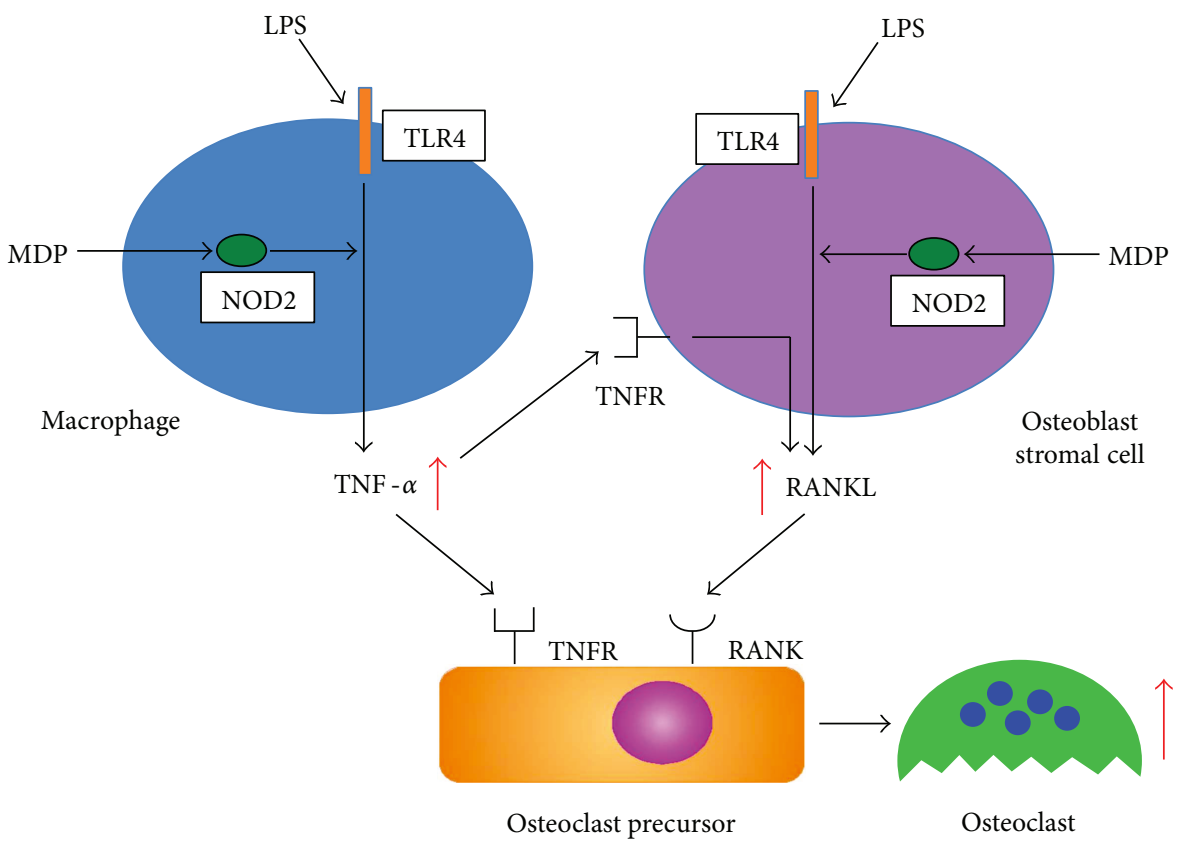

FIGURE 2: Schematic of the role of MDP in LPS-induced osteoclast formation. LPS induces TNF- $\alpha$ expression; MDP further enhances this TNF- $\alpha$ expression. MDP-enhanced, LPS-induced TNF- $\alpha$ may lead to an increase in RANKL expression by stromal cells. Furthermore, LPS also acts to induce RANKL expression; MDP further enhances this RANKL expression in stromal cells. The MDP-enhanced, LPSinduced TNF- $\alpha$ production synergistically interacts with MDP-enhanced, LPS-induced RANKL, thereby leading to increased induction of osteoclastogenesis. Therefore, the role of MDP in LPS-induced osteoclast formation in vivo may be to strongly promote the induction of this process.

LPS exposure induces TNF- $\alpha$ expression in macrophages and other immune cells; MDP exposure enhances this LPSinduced TNF- $\alpha$ expression. TNF- $\alpha$ stimulation increases RANKL expression by stromal cells $[18,101-103]$. Therefore, LPS-induced TNF- $\alpha$, which has been further enhanced by MDP, may greatly increase RANKL expression by stromal cells. Furthermore, LPS acts to induce RANKL expression in stromal cells, and MDP also enhances this LPSinduced RANKL expression. TNF- $\alpha$ promotes osteoclast formation by osteoclast precursors by synergizing with RANKL $[104,105]$ at the signal transduction level $[15,18,104-106]$. This suggests that TNF- $\alpha$ synergistically increases RANKLinduced osteoclast formation. Therefore, LPS-induced TNF- $\alpha$ production is enhanced by MDP and synergistically interacts with RANKL, leading to a large induction of osteoclastogenesis (Figure 2). Thus, the role of MDP in LPS-induced osteoclast formation in vivo may be to strongly promote the induction of this process.

\section{Conclusions}

LPS plays a key role in the induction of important biological activities such as inflammation. LPS induces osteoclast formation during inflammatory processes, such as periodontal disease. MDP exposure enhances LPS-induced biological activities, including osteoclast formation and bone destruction, through a mechanism that is gradually becoming clear. Therefore, targeted therapies against LPS and MDP could serve an important role in management of inflammatory disease processes. Further studies are required to fully understand the mechanisms of LPS- and MDP-mediated biological activities, especially osteoclast formation.

\section{Conflicts of Interest}

The authors declare that there is no conflict of interest regarding the publication of this paper.

\section{References}

[1] Y. Abu-Amer, F. P. Ross, J. Edwards, and S. L. Teitelbaum, "Lipopolysaccharide-stimulated osteoclastogenesis is mediated by tumor necrosis factor via its $\mathrm{P} 55$ receptor," The Journal of Clinical Investigation, vol. 100, no. 6, pp. 1557-1565, 1997.

[2] C. Y. Chiang, G. Kyritsis, D. T. Graves, and S. Amar, "Interleukin-1 and tumor necrosis factor activities partially account for calvarial bone resorption induced by local injection of lipopolysaccharide," Infection and Immunity, vol. 67, no. 8, pp. 4231-4236, 1999.

[3] P. Khedoe, S. de Kleijn, A. M. van Oeveren-Rietdijk et al., "Acute and chronic effects of treatment with mesenchymal stromal cells on LPS-induced pulmonary inflammation, emphysema and atherosclerosis development," PLoS One, vol. 12, no. 9, article e0183741, 2017.

[4] C. V. Rosadini and J. C. Kagan, "Early innate immune responses to bacterial LPS," Current Opinion in Immunology, vol. 44, pp. 14-19, 2017.

[5] P. C. Lopes, "LPS and neuroinflammation: a matter of timing," Inflammopharmacology, vol. 24, no. 5, pp. 291-293, 2016. 
[6] S. Steven, M. Dib, S. Roohani, F. Kashani, T. Munzel, and A. Daiber, "Time response of oxidative/nitrosative stress and inflammation in LPS-induced endotoxaemia-a comparative study of mice and rats," International Journal of Molecular Sciences, vol. 18, no. 10, article 2176, 2017.

[7] G. Yucel, Z. Zhao, I. El-Battrawy et al., "Lipopolysaccharides induced inflammatory responses and electrophysiological dysfunctions in human-induced pluripotent stem cell derived cardiomyocytes," Scientific Reports, vol. 7, no. 1, article 2935, 2017.

[8] S. Hong and J. W. Yu, "Prolonged exposure of lipopolysaccharide induces NLRP3-independent maturation and secretion of interleukin (IL)- $1 \beta$ in macrophages," Journal of Microbiology and Biotechnology, 2017.

[9] H. Takada, S. Yokoyama, and S. Yang, "Enhancement of endotoxin activity by muramyldipeptide," Journal of Endotoxin Research, vol. 8, no. 5, pp. 337-342, 2002.

[10] H. Takada and C. Galanos, "Enhancement of endotoxin lethality and generation of anaphylactoid reactions by lipopolysaccharides in muramyl-dipeptide-treated mice," Infection and Immunity, vol. 55, no. 2, pp. 409-413, 1987.

[11] S. Yang, R. Tamai, S. Akashi et al., "Synergistic effect of muramyldipeptide with lipopolysaccharide or lipoteichoic acid to induce inflammatory cytokines in human monocytic cells in culture," Infection and Immunity, vol. 69, no. 4, pp. 2045-2053, 2001.

[12] S. L. Teitelbaum, "Bone resorption by osteoclasts," Science, vol. 289, no. 5484, pp. 1504-1508, 2000.

[13] Y. Azuma, K. Kaji, R. Katogi, S. Takeshita, and A. Kudo, "Tumor necrosis factor- $\alpha$ induces differentiation of and bone resorption by osteoclasts," The Journal of Biological Chemistry, vol. 275, no. 7, pp. 4858-4864, 2000.

[14] K. Kobayashi, N. Takahashi, E. Jimi et al., "Tumor necrosis factor alpha stimulates osteoclast differentiation by a mechanism independent of the ODF/RANKL-RANK interaction," The Journal of Experimental Medicine, vol. 191, no. 2, pp. 275-286, 2000.

[15] K. Fuller, C. Murphy, B. Kirstein, S. W. Fox, and T. J. Chambers, "TNF $\alpha$ potently activates osteoclasts, through a direct action independent of and strongly synergistic with RANKL," Endocrinology, vol. 143, no. 3, pp. 1108-1118, 2002.

[16] Y. Cao, I. D. C. Jansen, S. Sprangers, T. J. de Vries, and V. Everts, "TNF- $\alpha$ has both stimulatory and inhibitory effects on mouse monocyte-derived osteoclastogenesis," Journal of Cellular Physiology, vol. 232, no. 12, pp. 3273-3285, 2017.

[17] H. Kitaura, M. S. Sands, K. Aya et al., "Marrow stromal cells and osteoclast precursors differentially contribute to TNF$\alpha$-induced osteoclastogenesis in vivo," The Journal of Immunology, vol. 173, no. 8, pp. 4838-4846, 2004.

[18] H. Kitaura, P. Zhou, H. J. Kim, D. V. Novack, F. P. Ross, and S. L. Teitelbaum, "M-CSF mediates TNF-induced inflammatory osteolysis," The Journal of Clinical Investigation, vol. 115, no. 12, pp. 3418-3427, 2005.

[19] W. Zou and Z. Bar-Shavit, "Dual modulation of osteoclast differentiation by lipopolysaccharide," Journal of Bone and Mineral Research, vol. 17, no. 7, pp. 1211-1218, 2002.

[20] A. I. Espirito Santo, A. Ersek, A. Freidin, M. Feldmann, A. A. Stoop, and N. J. Horwood, "Selective inhibition of TNFR1 reduces osteoclast numbers and is differentiated from antiTNF in a LPS-driven model of inflammatory bone loss,"
Biochemical and Biophysical Research Communications, vol. 464, no. 4, pp. 1145-1150, 2015.

[21] S. Islam, F. Hassan, G. Tumurkhuu et al., "Bacterial lipopolysaccharide induces osteoclast formation in RAW 264.7 macrophage cells," Biochemical and Biophysical Research Communications, vol. 360, no. 2, pp. 346-351, 2007.

[22] M. Mormann, M. Thederan, I. Nackchbandi, T. Giese, C. Wagner, and G. M. Hansch, "Lipopolysaccharides (LPS) induce the differentiation of human monocytes to osteoclasts in a tumour necrosis factor (TNF) $\alpha$-dependent manner: a link between infection and pathological bone resorption," Molecular Immunology, vol. 45, no. 12, pp. 3330-3337, 2008.

[23] H. Mizutani, Y. Ishihara, A. Izawa et al., "Lipopolysaccharide of Aggregatibacter actinomycetemcomitans up-regulates inflammatory cytokines, prostaglandin $\mathrm{E}_{2}$ synthesis and osteoclast formation in interleukin-1 receptor antagonistdeficient mice," Journal of Periodontal Research, vol. 48, no. 6, pp. 748-756, 2013.

[24] M. Ishida, H. Kitaura, K. Kimura et al., "Muramyl dipeptide enhances lipopolysaccharide-induced osteoclast formation and bone resorption through increased RANKL expression in stromal cells," Journal of Immunology Research, vol. 2015, Article ID 132765, 12 pages, 2015.

[25] E. T. Rietschel, T. Kirikae, F. U. Schade et al., "Bacterial endotoxin: molecular relationships of structure to activity and function," The FASEB Journal, vol. 8, no. 2, pp. 217-225, 1994.

[26] A. Steimle, I. B. Autenrieth, and J. S. Frick, "Structure and function: lipid A modifications in commensals and pathogens," International Journal of Medical Microbiology, vol. 306, no. 5, pp. 290-301, 2016.

[27] R. R. Schumann, S. R. Leong, G. W. Flaggs et al., "Structure and function of lipopolysaccharide binding protein," Science, vol. 249, no. 4975, pp. 1429-1431, 1990.

[28] H. Fang, A. Liu, J. Sun, A. Kitz, O. Dirsch, and U. Dahmen, "Granulocyte colony stimulating factor induces lipopolysaccharide (LPS) sensitization via upregulation of LPS binding protein in rat," PLoS One, vol. 8, no. 2, article e56654, 2013.

[29] S. D. Wright, R. A. Ramos, P. S. Tobias, R. J. Ulevitch, and J. C. Mathison, "CD14, a receptor for complexes of lipopolysaccharide (LPS) and LPS binding protein," Science, vol. 249, no. 4975 , pp. $1431-1433,1990$.

[30] L. Fang, Z. Xu, G. S. Wang et al., "Directed evolution of an LBP/CD14 inhibitory peptide and its anti-endotoxin activity," PLoS One, vol. 9, no. 7, article e101406, 2014.

[31] R. Shimazu, S. Akashi, H. Ogata et al., "MD-2, a molecule that confers lipopolysaccharide responsiveness on Toll-like receptor 4," The Journal of Experimental Medicine, vol. 189, no. 11, pp. 1777-1782, 1999.

[32] R. Medzhitov, "Toll-like receptors and innate immunity," Nature Reviews Immunology, vol. 1, no. 2, pp. 135-145, 2001.

[33] B. S. Park and J. O. Lee, "Recognition of lipopolysaccharide pattern by TLR4 complexes," Experimental \& Molecular Medicine, vol. 45, no. 12, article e66, 2013.

[34] H. D. Brightbill and R. L. Modlin, "Toll-like receptors: molecular mechanisms of the mammalian immune response," Immunology, vol. 101, no. 1, pp. 1-10, 2000.

[35] T. Tajima, T. Murata, K. Aritake et al., "Lipopolysaccharide induces macrophage migration via prostaglandin $\mathrm{D}_{2}$ and prostaglandin $\mathrm{E}_{2}$," The Journal of Pharmacology and Experimental Therapeutics, vol. 326, no. 2, pp. 493-501, 2008. 
[36] A. K. Kiemer, C. Muller, and A. M. Vollmar, "Inhibition of LPS-induced nitric oxide and TNF- $\alpha$ production by $\alpha$ lipoic acid in rat Kupffer cells and in RAW 264.7 murine macrophages," Immunology \& Cell Biology, vol. 80, no. 6, pp. 550-557, 2002.

[37] M. Rossol, H. Heine, U. Meusch et al., "LPS-induced cytokine production in human monocytes and macrophages," Critical Reviews in Immunology, vol. 31, no. 5, pp. 379-446, 2011.

[38] H. B. Xiao, C. R. Wang, Z. K. Liu, and J. Y. Wang, "LPS induces pro-inflammatory response in mastitis mice and mammary epithelial cells: possible involvement of NF$\kappa$ Bsignaling and OPN," Pathologie Biologie, vol. 63, no. 1, pp. 11-16, 2015.

[39] J. van Heijenoort, "Formation of the glycan chains in the synthesis of bacterial peptidoglycan," Glycobiology, vol. 11, no. 3, pp. 25R-36R, 2001.

[40] R. Wheeler, G. Chevalier, G. Eberl, and I. Gomperts Boneca, "The biology of bacterial peptidoglycans and their impact on host immunity and physiology," Cellular Microbiology, vol. 16, no. 7, pp. 1014-1023, 2014.

[41] M. Chamaillard, M. Hashimoto, Y. Horie et al., “An essential role for NOD1 in host recognition of bacterial peptidoglycan containing diaminopimelic acid," Nature Immunology, vol. 4, no. 7, pp. 702-707, 2003.

[42] S. E. Girardin, I. G. Boneca, J. Viala et al., "Nod2 is a general sensor of peptidoglycan through muramyl dipeptide (MDP) detection," The Journal of Biological Chemistry, vol. 278, no. 11, pp. 8869-8872, 2003.

[43] F. Ellouz, A. Adam, R. Ciorbaru, and E. Lederer, "Minimal structural requirements for adjuvant activity of bacterial peptidoglycan derivatives," Biochemical and Biophysical Research Communications, vol. 59, no. 4, pp. 1317-1325, 1974.

[44] C. Merser, P. Sinay, and A. Adam, "Total synthesis and adjuvant activity of bacterial peptidoglycan derivatives," Biochemical and Biophysical Research Communications, vol. 66, no. 4, pp. 1316-1322, 1975.

[45] H. S. Warren, F. R. Vogel, and L. A. Chedid, "Current status of immunological adjuvants," Annual Review of Immunology, vol. 4, no. 1, pp. 369-388, 1986.

[46] L. Z. Wang, L. Zhang, L. L. Wang et al., "Muramyl dipeptide and anti-CD10 monoclonal antibody immunoconjugate enhances anti-leukemia immunity of T lymphocytes," APMIS, vol. 124, no. 9, pp. 800-804, 2016.

[47] T. O'Reilly and O. Zak, "Enhancement of the effectiveness of antimicrobial therapy by muramyl peptide immunomodulators," Clinical Infectious Diseases, vol. 14, no. 5, pp. 11001109, 1992.

[48] E. C. Darcissac, G. M. Bahr, M. A. Parant, L. A. Chedid, and G. J. Riveau, "Selective induction of CD11a,b,c/CD18 and CD54 expression at the cell surface of human leukocytes by muramyl peptides," Cellular Immunology, vol. 169, no. 2, pp. 294-301, 1996.

[49] M. Heinzelmann, H. C. Polk Jr, A. Chernobelsky, T. P. Stites, and L. E. Gordon, "Endotoxin and muramyl dipeptide modulate surface receptor expression on human mononuclear cells," Immunopharmacology, vol. 48, no. 2, pp. 117-128, 2000.

[50] I. Morisaki, S. M. Michalek, C. C. Harmon, M. Torii, S. Hamada, and J. R. McGhee, "Effective immunity to dental caries: enhancement of salivary anti-Streptococcus mutans antibody responses with oral adjuvants," Infection and Immunity, vol. 40, no. 2, pp. 577-591, 1983.

[51] M. M. Willems, G. G. Zom, N. Meeuwenoord et al., "Lipophilic muramyl dipeptide-antigen conjugates as immunostimulating agents," ChemMedChem, vol. 11, no. 2, pp. 190198, 2016.

[52] L. Chedid, "Muramyl peptides as possible endogenous immunopharmacological mediators," Microbiology and Immunology, vol. 27, no. 9, pp. 723-732, 1983.

[53] S. Traub, S. von Aulock, T. Hartung, and C. Hermann, "MDP and other muropeptides-direct and synergistic effects on the immune system," Journal of Endotoxin Research, vol. 12, no. 2, pp. 69-85, 2006.

[54] I. Saiki and I. J. Fidler, "Synergistic activation by recombinant mouse interferon-gamma and muramyl dipeptide of tumoricidal properties in mouse macrophages," The Journal of Immunology, vol. 135, no. 1, pp. 684-688, 1985.

[55] V. Souvannavong, S. Brown, and A. Adam, "Muramyl dipeptide (MDP) synergizes with interleukin 2 and interleukin 4 to stimulate, respectively, the differentiation and proliferation of B cells," Cellular Immunology, vol. 126, no. 1, pp. 106-116, 1990.

[56] M. A. Wolfert, T. F. Murray, G. J. Boons, and J. N. Moore, "The origin of the synergistic effect of muramyl dipeptide with endotoxin and peptidoglycan," The Journal of Biological Chemistry, vol. 277, no. 42, pp. 39179-39186, 2002.

[57] J. E. Wang, P. F. Jorgensen, E. A. Ellingsen et al., "Peptidoglycan primes for LPS-induced release of proinflammatory cytokines in whole human blood," Shock, vol. 16, no. 3, pp. 178$182,2001$.

[58] S. Traub, N. Kubasch, S. Morath et al., "Structural requirements of synthetic muropeptides to synergize with lipopolysaccharide in cytokine induction," The Journal of Biological Chemistry, vol. 279, no. 10, pp. 8694-8700, 2004.

[59] P. F. Jorgensen, J. E. Wang, M. Almlof et al., "Peptidoglycan and lipoteichoic acid modify monocyte phenotype in human whole blood," Clinical and Vaccine Immunology, vol. 8, no. 3, pp. 515-521, 2001.

[60] M. G. Netea, G. Ferwerda, D. J. de Jong et al., "Nucleotidebinding oligomerization domain-2 modulates specific TLR pathways for the induction of cytokine release," The Journal of Immunology, vol. 174, no. 10, pp. 6518-6523, 2005.

[61] T. Selvanantham, N. K. Escalante, M. Cruz Tleugabulova et al., "Nod1 and Nod2 enhance TLR-mediated invariant NKT cell activation during bacterial infection," The Journal of Immunology, vol. 191, no. 11, pp. 5646-5654, 2013.

[62] P. R. Pouillart, F. M. Audibert, L. A. Chedid, P. L. Lefrancier, and G. M. Bahr, "Enhancement by muramyl peptides of the protective response of interferon- $\alpha / \beta$ against encephalomyocarditis virus infection," International Journal of Immunopharmacology, vol. 18, no. 3, pp. 183-192, 1996.

[63] J. J. Killion and I. J. Fidler, "Therapy of cancer metastasis by tumoricidal activation of tissue macrophages using liposome-encapsulated immunomodulators," Pharmacology \& Therapeutics, vol. 78, no. 3, pp. 141-154, 1998.

[64] S. Srividya, R. P. Roy, S. K. Basu, and A. Mukhopadhyay, "Selective activation of antitumor activity of macrophages by the delivery of muramyl dipeptide using a novel polynucleotide-based carrier recognized by scavenger receptors," Biochemical and Biophysical Research Communications, vol. 268, no. 3, pp. 772-777, 2000. 
[65] Y. Dong, S. Wang, C. Wang, Z. Li, Y. Ma, and G. Liu, “Antagonizing NOD2 signaling with conjugates of paclitaxel and muramyl dipeptide derivatives sensitizes paclitaxel therapy and significantly prevents tumor metastasis," Journal of Medicinal Chemistry, vol. 60, no. 3, pp. 1219-1224, 2017.

[66] X. Li, J. Yu, S. Xu et al., "Chemical conjugation of muramyl dipeptide and paclitaxel to explore the combination of immunotherapy and chemotherapy for cancer," Glycoconjugate Journal, vol. 25, no. 5, pp. 415-425, 2008.

[67] Z. Jakopin, "Murabutide revisited: a review of its pleiotropic biological effects," Current Medicinal Chemistry, vol. 20, no. 16, pp. 2068-2079, 2013.

[68] L. A. Chedid, M. A. Parant, F. M. Audibert et al., "Biological activity of a new synthetic muramyl peptide adjuvant devoid of pyrogenicity," Infection and Immunity, vol. 35, no. 2, pp. 417-424, 1982.

[69] M. A. Parant, P. Pouillart, C. Le Contel, F. J. Parant, L. A. Chedid, and G. M. Bahr, "Selective modulation of lipopolysaccharide-induced death and cytokine production by various muramyl peptides," Infection and Immunity, vol. 63, no. 1, pp. 110-115, 1995.

[70] T. Goasduff, E. C. Darcissac, V. Vidal, A. Capron, and G. M. Bahr, "The transcriptional response of human macrophages to murabutide reflects a spectrum of biological effects for the synthetic immunomodulator," Clinical \& Experimental Immunology, vol. 128, no. 3, pp. 474-482, 2002.

[71] E. C. Darcissac, M. J. Truong, J. Dewulf, Y. Mouton, A. Capron, and G. M. Bahr, "The synthetic immunomodulator murabutide controls human immunodeficiency virus type 1 replication at multiple levels in macrophages and dendritic cells," Journal of Virology, vol. 74, no. 17, pp. 7794-7802, 2000.

[72] E. M. Jackson and M. M. Herbst-Kralovetz, "Intranasal vaccination with murabutide enhances humoral and mucosal immune responses to a virus-like particle vaccine," PLoS One, vol. 7, no. 7, article e41529, 2012.

[73] V. F. Vidal, N. Casteran, C. J. Riendeau et al., "Macrophage stimulation with Murabutide, an HIV-suppressive muramyl peptide derivative, selectively activates extracellular signalregulated kinases 1 and 2, $\mathrm{C} / \mathrm{EBP} \beta$ and STAT1: role of CD14 and Toll-like receptors 2 and 4," European Journal of Immunology, vol. 31, no. 7, pp. 1962-1971, 2001.

[74] G. M. Bahr, E. Darcissac, P. R. Pouillart, and L. A. Chedid, "Synergistic effects between recombinant interleukin-2 and the synthetic immunomodulator murabutide: selective enhancement of cytokine release and potentiation of antitumor activity," Journal of Interferon \& Cytokine Research, vol. 16, no. 2, pp. 169-178, 1996.

[75] K. Redlich, S. Hayer, R. Ricci et al., "Osteoclasts are essential for TNF- $\alpha$-mediated joint destruction," The Journal of Clinical Investigation, vol. 110, no. 10, pp. 1419-1427, 2002.

[76] K. D. Merkel, J. M. Erdmann, K. P. McHugh, Y. Abu-Amer, F. P. Ross, and S. L. Teitelbaum, "Tumor necrosis factor- $\alpha$ mediates orthopedic implant osteolysis," The American Journal of Pathology, vol. 154, no. 1, pp. 203-210, 1999.

[77] R. B. Kimble, S. Srivastava, F. P. Ross, A. Matayoshi, and R. Pacifici, "Estrogen deficiency increases the ability of stromal cells to support murine osteoclastogenesis via an interleukin-1 and tumor necrosis factor-mediated stimulation of macrophage colony-stimulating factor production," The Journal of Biological Chemistry, vol. 271, no. 46, pp. 28890-28897, 1996.
[78] T. Duong le, A. T. Leung, and B. Langdahl, "Cathepsin K inhibition: a new mechanism for the treatment of osteoporosis," Calcified Tissue International, vol. 98, no. 4, pp. 381-397, 2016.

[79] S. A. Hienz, S. Paliwal, and S. Ivanovski, "Mechanisms of bone resorption in periodontitis," Journal of Immunology Research, vol. 2015, Article ID 615486, 10 pages, 2015.

[80] T. Kikuchi, T. Matsuguchi, N. Tsuboi et al., "Gene expression of osteoclast differentiation factor is induced by lipopolysaccharide in mouse osteoblasts via Toll-like receptors," The Journal of Immunology, vol. 166, no. 5, pp. 3574-3579, 2001.

[81] H. Kitaura, K. Kimura, M. Ishida, H. Kohara, M. Yoshimatsu, and T. Takano-Yamamoto, "Immunological reaction in TNF- $\alpha$-mediated osteoclast formation and bone resorption in vitro and in vivo," Clinical \& Developmental Immunology, vol. 2013, article 181849, 8 pages, 2013.

[82] S. Wei, M. W. Wang, S. L. Teitelbaum, and F. P. Ross, "Interleukin-4 reversibly inhibits osteoclastogenesis via inhibition of NF- $\kappa \mathrm{B}$ and mitogen-activated protein kinase signaling," The Journal of Biological Chemistry, vol. 277, no. 8, pp. 6622-6630, 2002.

[83] H. Kitaura, N. Nagata, Y. Fujimura et al., "Interleukin-4 directly inhibits tumor necrosis factor- $\alpha$-mediated osteoclast formation in mouse bone marrow macrophages," Immunology Letters, vol. 88, no. 3, pp. 193-198, 2003.

[84] T. Fujii, H. Kitaura, K. Kimura, Z. W. Hakami, and T. Takano-Yamamoto, "IL-4 inhibits TNF- $\alpha$-mediated osteoclast formation by inhibition of RANKL expression in TNF- $\alpha$-activated stromal cells and direct inhibition of TNF$\alpha$-activated osteoclast precursors via a T-cell-independent mechanism in vivo," Bone, vol. 51, no. 4, pp. 771-780, 2012.

[85] M. S. Freire, A. P. C. Cantuaria, S. M. F. Lima et al., "NanoUPLC-MS ${ }^{\mathrm{E}}$ proteomic analysis of osteoclastogenesis downregulation by IL-4," Journal of Proteomics, vol. 131, pp. 8-16, 2016.

[86] Y. Hu, B. Ek-Rylander, M. Wendel, and G. Andersson, "Reciprocal effects of interferon- $\gamma$ and IL- 4 on differentiation to osteoclast-like cells by RANKL or LPS," Oral Diseases, vol. 20, no. 7, pp. 682-692, 2014.

[87] M. Yoshimatsu, H. Kitaura, Y. Fujimura, H. Kohara, Y. Morita, and N. Yoshida, "IL-12 inhibits lipopolysaccharide stimulated osteoclastogenesis in mice," Journal of Immunology Research, vol. 2015, Article ID 214878, 8 pages, 2015.

[88] J. Saeed, H. Kitaura, K. Kimura et al., "IL-37 inhibits lipopolysaccharide-induced osteoclast formation and bone resorption in vivo," Immunology Letters, vol. 175, pp. 8-15, 2016.

[89] S. Yang, N. Takahashi, T. Yamashita et al., "Muramyl dipeptide enhances osteoclast formation induced by lipopolysaccharide, IL- $1 \alpha$, and TNF- $\alpha$ through nucleotide-binding oligomerization domain 2-mediated signaling in osteoblasts," The Journal of Immunology, vol. 175, no. 3, pp. 1956-1964, 2005.

[90] T. Kishimoto, T. Kaneko, T. Ukai et al., "Peptidoglycan and lipopolysaccharide synergistically enhance bone resorption and osteoclastogenesis," Journal of Periodontal Research, vol. 47, no. 4, pp. 446-454, 2012.

[91] J. C. Chow, D. W. Young, D. T. Golenbock, W. J. Christ, and F. Gusovsky, "Toll-like receptor-4 mediates lipopoly saccharide-induced signal transduction," The Journal of Biological Chemistry, vol. 274, no. 16, pp. 10689-10692, 1999. 
[92] G. L. Su, R. D. Klein, A. Aminlari et al., "Kupffer cell activation by lipopolysaccharide in rats: role for lipopolysaccharide binding protein and toll-like receptor 4," Hepatology, vol. 31, no. 4, pp. 932-936, 2000.

[93] K. Lucas and M. Maes, "Role of the toll like receptor (TLR) radical cycle in chronic inflammation: possible treatments targeting the TLR4 pathway," Molecular Neurobiology, vol. 48, no. 1, pp. 190-204, 2013.

[94] B. Beutler, "TLR4 as the mammalian endotoxin sensor," Current Topics in Microbiology and Immunology, vol. 270, pp. 109-120, 2002.

[95] B. Beutler, Z. Jiang, P. Georgel et al., "Genetic analysis of host resistance: toll-like receptor signaling and immunity at large," Annual Review of Immunology, vol. 24, no. 1, pp. 353-389, 2006.

[96] E. M. Palsson-McDermott and L. A. O'Neill, "Signal transduction by the lipopolysaccharide receptor, toll-like receptor-4," Immunology, vol. 113, no. 2, pp. 153-162, 2004.

[97] C. Dai, L. Sun, L. Yu, G. Zhu, S. Wu, and W. Bao, "Effects of porcine $M y D 88$ knockdown on the expression of TLR4 pathway-related genes and proinflammatory cytokines," Bioscience Reports, vol. 36, no. 6, article e00409, 2016.

[98] L. Tang, X. D. Zhou, Q. Wang et al., "Expression of TRAF6 and pro-inflammatory cytokines through activation of TLR2, TLR4, NOD1, and NOD2 in human periodontal ligament fibroblasts," Archives of Oral Biology, vol. 56, no. 10, pp. 1064-1072, 2011.

[99] K. Bandow, A. Maeda, K. Kakimoto et al., "Molecular mechanisms of the inhibitory effect of lipopolysaccharide (LPS) on osteoblast differentiation," Biochemical and Biophysical Research Communications, vol. 402, no. 4, pp. 755-761, 2010.

[100] J. Nakao, Y. Fujii, J. Kusuyama et al., "Low-intensity pulsed ultrasound (LIPUS) inhibits LPS-induced inflammatory responses of osteoblasts through TLR4-MyD88 dissociation," Bone, vol. 58, pp. 17-25, 2014.

[101] L. C. Hofbauer, D. L. Lacey, C. R. Dunstan, T. C. Spelsberg, B. L. Riggs, and S. Khosla, "Interleukin- $1 \beta$ and tumor necrosis factor- $\alpha$, but not interleukin-6, stimulate osteoprotegerin ligand gene expression in human osteoblastic cells," Bone, vol. 25, no. 3, pp. 255-259, 1999.

[102] J. Sun and Y. Ding, "NOD2 agonist promotes the production of inflammatory cytokines in VSMC in synergy with TLR2 and TLR4 agonists," The Scientific World Journal, vol. 2012, Article ID 607157, 4 pages, 2012.

[103] M. C. Walsh and Y. Choi, "Biology of the RANKL-RANKOPG system in immunity, bone, and beyond," Frontiers in Immunology, vol. 5, p. 511, 2014.

[104] J. Lam, S. Takeshita, J. E. Barker, O. Kanagawa, F. P. Ross, and S. L. Teitelbaum, "TNF- $\alpha$ induces osteoclastogenesis by direct stimulation of macrophages exposed to permissive levels of RANK ligand," The Journal of Clinical Investigation, vol. 106, no. 12, pp. 1481-1488, 2000.
[105] Y. H. Zhang, A. Heulsmann, M. M. Tondravi, A. Mukherjee, and Y. Abu-Amer, "Tumor necrosis factor- $\alpha$ (TNF) stimulates RANKL-induced osteoclastogenesis via coupling of TNF type 1 receptor and RANK signaling pathways," The Journal of Biological Chemistry, vol. 276, no. 1, pp. 563-568, 2001.

[106] Z. Yao, W. Lei, R. Duan, Y. Li, L. Luo, and B. F. Boyce, "RANKL cytokine enhances TNF-induced osteoclastogenesis independently of TNF receptor associated factor (TRAF) 6 by degrading TRAF3 in osteoclast precursors," The Journal of Biological Chemistry, vol. 292, no. 24, pp. 10169-10179, 2017. 


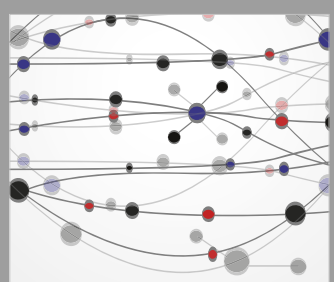

The Scientific World Journal
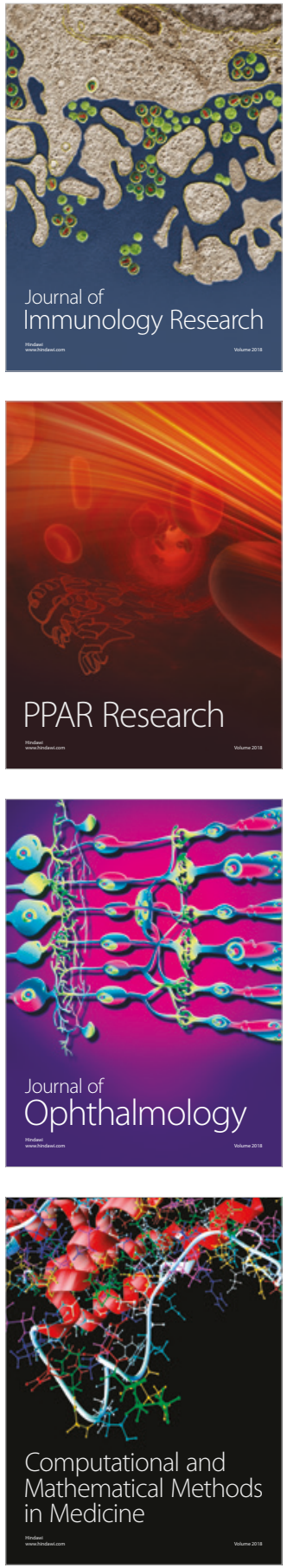

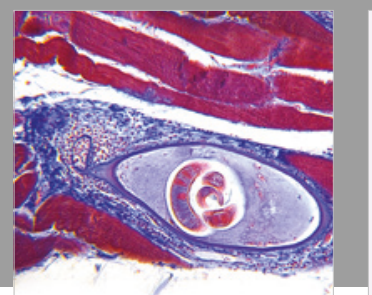

Gastroenterology Research and Practice

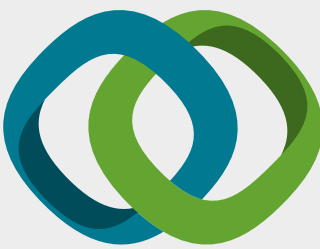

\section{Hindawi}

Submit your manuscripts at

www.hindawi.com
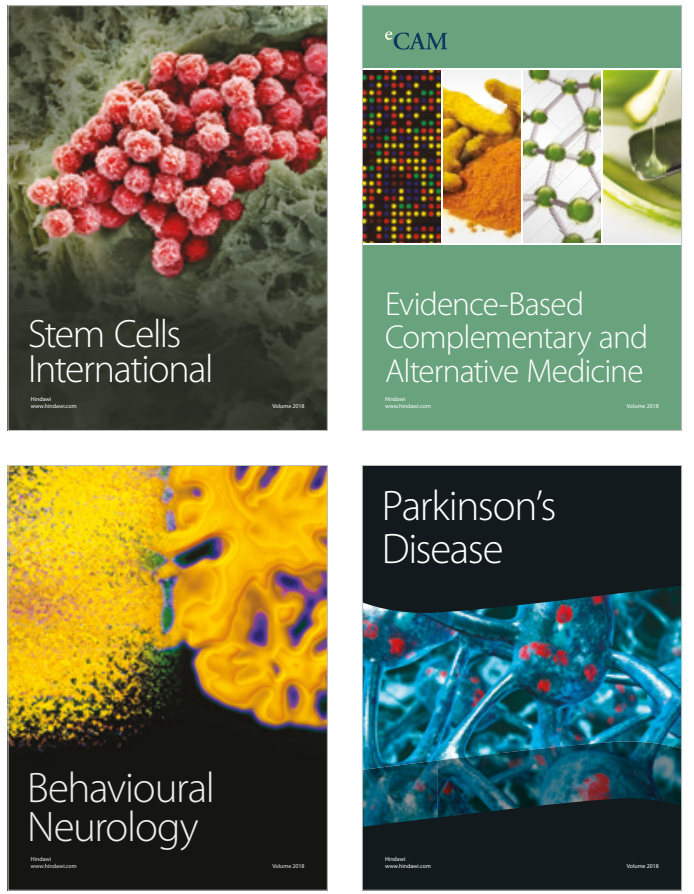

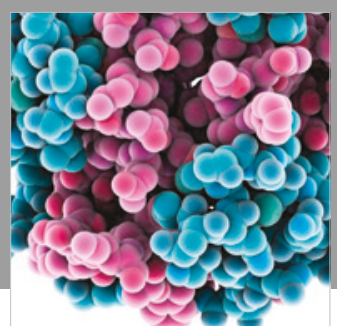

ournal of

Diabetes Research

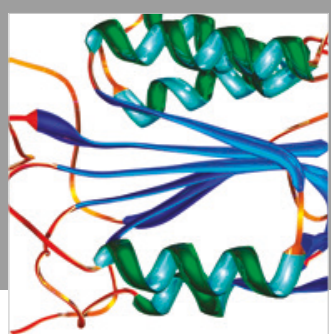

Disease Markers
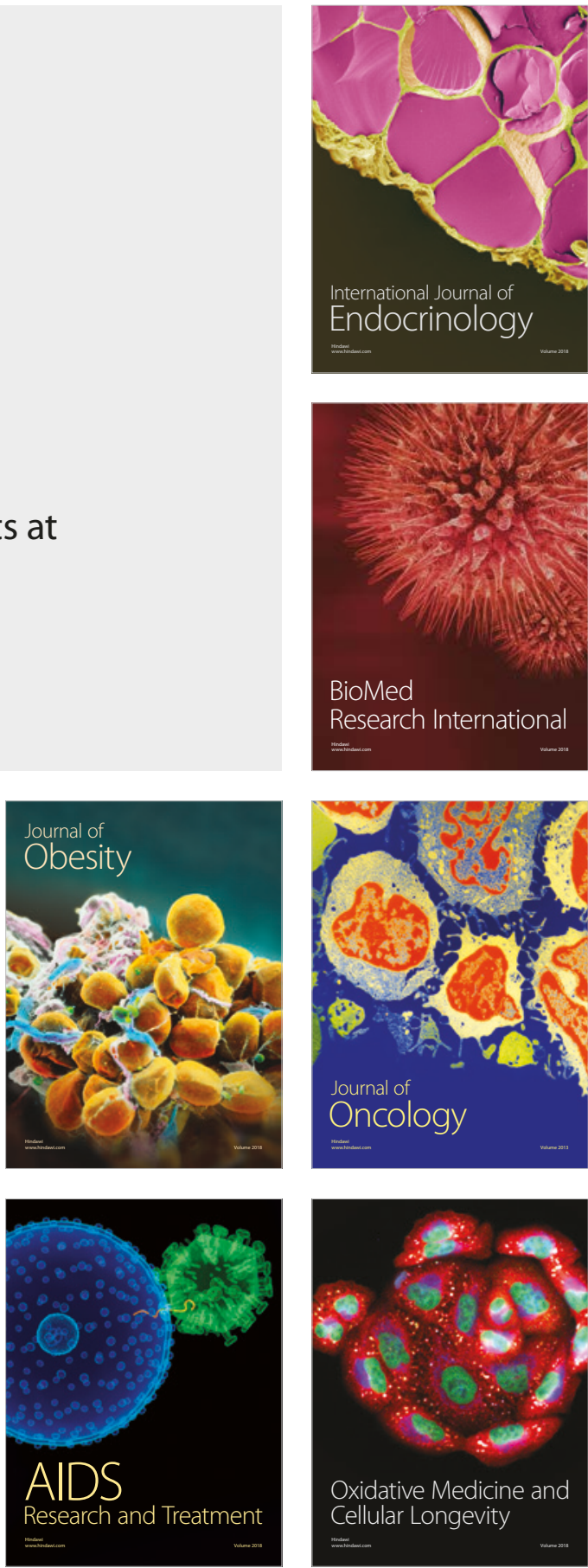